\title{
The effect of laryngoscope types on hemodynamic response and optic nerve sheath diameter
}

\author{
McCoy, Macintosh, and C-MAC video-laryngoscope
}

Gamze Küçükosman, MD, Bengü G. Aydın, MD, Necla Gülçek, MD, Rahşan D. Okyay, MD, Özcan Pişkin, MD, Hilal Ayoğlu, MD.

\begin{abstract}

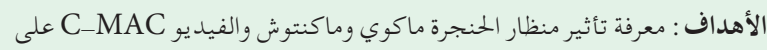

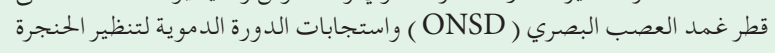
والتنبيب.

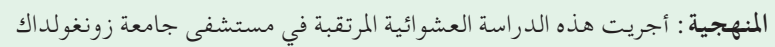

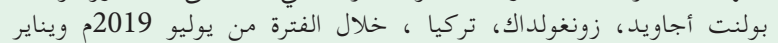

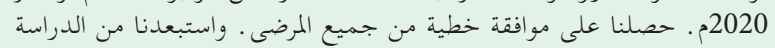

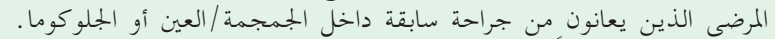

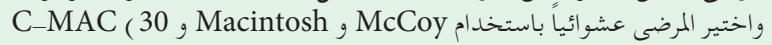

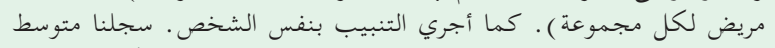

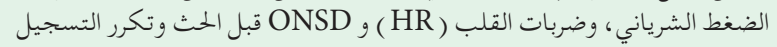
في الدقيقة 1 , 3, 5 و 10 بعد التنبيب.

النتائج : كانت تأثيرات منظار الحنجرة والتنبيب على استجابات الدورة الدموية

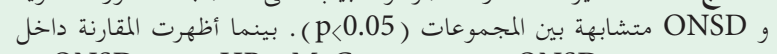

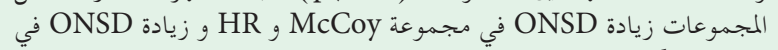

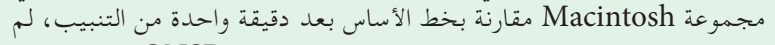

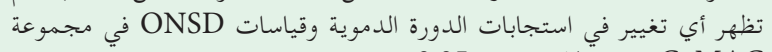
. القيمة الإحصائية ( C-MAC

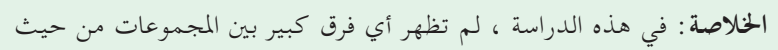

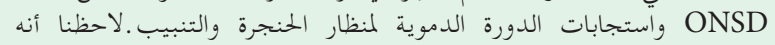

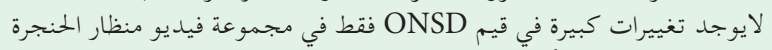
ماسب C-MAC

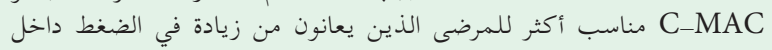
الجمجمة
\end{abstract}

Objectives: This study aims to investigate the effect of McCoy, Macintosh laryngoscope, and C-MAC videolaryngoscopes on optic nerve sheath diameter (ONSD) and hemodynamic responses to laryngoscopy and intubation.

Methods: This prospective randomized study was conducted in Zonguldak Bülent Ecevit University Hospital, Zonguldak, Turkey, between July 2019 and January 2020. Informed written consent was obtained from all patients. Patients with previous intracranial/ ocular surgery or glaucoma were excluded from the study. The patients were randomized to use McCoy,
Macintosh, and C-MAC (30 per group). Intubations were performed by the same person. Mean arterial pressure, heart rate (HR), and ONSD were recorded before the induction and repeated in 1, 3, 5, and 10 minutes after the intubation.

Results: The effects of laryngoscopy and intubation on hemodynamic responses and ONSD were similar between groups $(p>0.05)$. While the comparison within groups showed ONSD increase in McCoy group and HR and ONSD increase in the Macintosh group compared to baseline $1 \mathrm{~min}$ after the intubation, no change was observed in hemodynamic responses and ONSD measurements in the C-MAC group $(p>0.05)$.

Conclusions: In this study, there was no significant difference between the groups in terms of ONSD and hemodynamic responses to laryngoscopy and intubation. It was observed that there were no significant changes in $\mathrm{ONSD}$ values just in $\mathrm{C}^{-\mathrm{MAC}^{\bullet}}$ video-laryngoscope group. Therefore, intubations with $\mathrm{C}^{-\mathrm{MAC}^{\circ}}$ videolaryngoscope are thought to be more appropriate for patients with an increase in intracranial pressure.

Keywords: hemodynamic response, laryngoscope types, optic nerve sheath diameter

Saudi Med J 2020; Vol. 41 (9): 930-937 doi: 10.15537/smj.2020.9.25349

From the Department of Anesthesiology and Reanimation, Zonguldak Bülent Ecevit University, Zonguldak, Turkey.

Received 8th April 2020. Accepted 19th August 2020.

Address correspondence and reprint request to: Dr Gamze Küçükosman, Department of Anesthesiology and Reanimation, Faculty of Medicine, Bülent Ecevit University, Zonguldak,Turkey.E-mail: gamzebeu@gmail.com ORCID ID: https://orcid.org/0000-0001-5224-0258 
$\mathrm{E}$ ndotracheal intubation is the gold standard for ensuring airway safety in general anaesthesia applications. ${ }^{1}$ Stimulation of the supraglotticregion during laryngoscopy leads to an increase in plasma catecholamine concentration due to the activation of the sympathoadrenal system. ${ }^{2}$ After laryngoscopy and intubation, a temporary (approximately $5 \mathrm{~min}$ ) increase in heart rate (HR), blood pressure and intraocular and intracranial pressure (ICP) and undesirable effects such as arrhythmia and bronchoconstriction may occur. Hemodynamic changes vary among patients. Although healthy and young patients generally tolerate these reactions well, patients with limited coronary reserves (myocardial ischaemia, acute heart failure or severe arrhythmia) may suffer pathological consequences. ${ }^{1-4}$ Control of hemodynamic response caused by laryngoscopy and intubation is very important in the practice of anesthesia. Many studies have reported the possible importance of the choice of laryngoscope in reducing or preventing this response. . $^{5-}$ 23 Video-laryngoscopes have recently been introduced

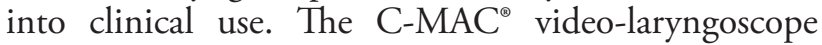
with Macintosh blade (KARL STORZ, Tuttlingen, Germany), which is designed for use in difficult airways, is frequently used. Although the C-MAC video-laryngoscope performs the same function as conventional laryngoscopes, it has been suggested that, by providing a larger laryngeal image with the help of the camera at the end of the laryngoscope blade, direct visualization of the glottis facilitates intubation and may reduce unwanted hemodynamic responses by reducing laryngeal irritation. ${ }^{10-13,16,18,21-23}$

Patients may be at heightened risk of increasing ICP during anesthesia and surgery for several reasons. ${ }^{24-33}$ Therefore, non-invasive methods, which can easily be applied in the operating room, have gained interest. Transocular ultrasound optic nerve sheath diameter (ONSD) measurement is the most prominent of these methods. ${ }^{26-36}$ When ICP increases, the sheath diameter is enlarged, and this change in diameter allows ICP to be evaluated indirectly by ultrasound via the optic nerve sheath. ${ }^{28}$

This study aimed to investigate the effects of 3 different laryngoscopes (the McCoy, and Macintosh laryngoscopes and the $\mathrm{C}-\mathrm{MAC}^{\bullet}$ video-laryngoscope) on laryngoscopy, ONSD, intubation and hemodynamic response in patients with normal airways.

Disclosure. Authors have no conflict of interests, and the work was not supported or funded by any drug company.
Methods. After receiving permission from the Zonguldak Bülent Ecevit University Research Ethics Committee (Date: 12/06/2019, No: 2019/09), this prospective randomized study was conducted in at the Zonguldak Bülent Ecevit University Hospital, Zonguldak, Turkey, between July 2019 and January 2020. Informed written consent was obtained from all patients. Ninety patients (aged 18-65 years) with an ASA score of I-II, who were scheduled for non ophthalmic elective surgery, were included in this study. The surgeries were performed under general anesthesia in the supine position and endotracheal intubation was performed. Patients with Mallampati and ASA status $\geq$ III, a history or suspicion of a difficult airway, those who had undergone intubation attempts more than 2 times, a history of intracranial/ocular surgery, cerebral edema or high ICP, glaucoma, uncontrolled hypertension, diabetic retinopathy and those who declined to participate were excluded. The demographic data, Mallampati and ASA status and intubation time (time from the insertion of the laryngoscope to the passage of the endotracheal tube through the glottis) of the patients were recorded.

The patients did not receive any premedication. Upon arrival at the operating room, an intravenous line was established, and normal saline was started. The patients were connected to a multichannel monitor that recorded the HR, non-invasive blood pressure, peripheral oxygen saturation $\left(\mathrm{SpO}_{2}\right)$, bispectral index (BIS) and train-of- 4 muscle relaxation. Bispectral index was used to monitor the depth of anesthesia and keep it between 40 and 60 . The patients were given $6 \mathrm{~L} / \mathrm{min}$ oxygen $\left(\mathrm{O}_{2}\right)$ through a face mask, and preoxygenation was started. A standardized anesthesia protocol that included propofol by $2.5 \mathrm{mg} / \mathrm{kg}$, fentanyl by $2 \mathrm{mcg} / \mathrm{kg}$ and $0.6 \mathrm{mg} / \mathrm{kg}$ of rocuronium was followed for all patients. Anesthesia was maintained with an inspiratory concentration of $2 \%$ sevoflurane and 50\% nitrous oxide in $\mathrm{O}_{2}$ at a fresh gas flow rate of $4 \mathrm{~L} / \mathrm{min}$.

Before anesthesia induction, all patients were randomly assigned to 3 groups using the sealed envelope technique: the McCoy laryngoscope group $(n=30)$, the Macintosh laryngoscope group $(\mathrm{n}=30)$ and the C-MAC ${ }^{\odot}$ video-laryngoscope group $(n=30)$. During intubation, a standard intubating pillow was used. The endotracheal tube sizes for the female patients were predetermined as $7.5 \mathrm{~mm}$ and male as $8.5 \mathrm{~mm}$. The endotracheal tubes were inserted via stylets with a 35 degrees "hockey stick" bend angle for all patients. A size 3 laryngoscope blade was used for all patients. All intubation procedures were performed by the same experienced anesthesia assistant who was familiar and trained (performed at least 50 
intubations prior to the study) with all 3 laryngoscopes. The endotracheal cuff pressure was standardized to 20 $\mathrm{cmH}_{2} \mathrm{O}$ via a manometer.

The patients' ONSDs were measured from both eyes using an EsaoteMyLab ${ }^{\text {тм }} 30$ (Gold, Genova, Italy) ultrasonography device while the patient was in the supine position. For the ONSD measurements, a water-soluble sterile gel was applied to the closed upper eyelid. The $7.5 \mathrm{MHz}$ linear ultrasound probe was carefully placed over the gel onto the upper eyelid. In the $\mathrm{M}$ mode, the entrance of the optic nerve to the orbital globe was imaged on the monitor without exerting excessive pressure. After finding the optimal contrast between the retrobulbar echogenic adipose tissue and the vertical hypoechogenic band, the ONSD was measured $3 \mathrm{~mm}$ behind the optic disc using an electronic calliper. The gel was wiped from the eyelid after the measurement was finished. The ONSD measurements were determined by averaging the values obtained from the transverse measurements of both eyes. The measurements for each patient were performed by 3 anesthesiologists who had received one week of training (approximately 20 measurements) prior to this study.The ONSD measurement values were determined for each patient by averaging the measurements taken by the 3 different anesthesiologists. The measurement results of each anesthesiologist were kept confidential from the other anesthesiologists. The hemodynamic variables (HR and mean arterial pressure [MAP]) and ONSD measurements were recorded immediately before induction (T0) and $1 \mathrm{~min}(\mathrm{~T} 1), 3 \mathrm{~min}$ (T3), $5 \mathrm{~min}$ (T5) and $10 \mathrm{~min}$ (T10) after intubation. All study parameters were collected and documented by the same observer, who did not know which type of laryngoscope was used. The laryngoscopy duration was measured with a stopwatch by an independent observer.
Statistical analysis. Statistical analysis was performed using the Statistical Package for Social Sciences version 23.0 (SPSS Inc.; Chicago, IL, USA). One-way ANOVA was used to compare the normally distributed data between the groups. Tukey's HSD and Tamhane's T2 tests were used for multiple comparisons. Repeatedmeasures ANOVA was used for the comparisons based on time within the groups. The planned sample size required to detect $95.9 \%$ test power $(1-\beta), 95 \%$ confidence $(1-\alpha)$ and effect size $d=1.16$ was 10 people per group. We included 30 patients in each group to compensate for patient dropouts. ${ }^{34}$ The results of the analyses are presented as mean \pm SD. A $p$-value of $<0.05$ was considered statistically significant.

Results. The target BIS level was obtained and maintained in all patients. No patient was excluded because of anesthetic depth failure. All patients were intubated at the first attempt. There was no difference between the groups in terms of demographic characteristics or Mallampati and ASA scores $(p>0.05)$ (Table 1). The intubation time was significantly longer

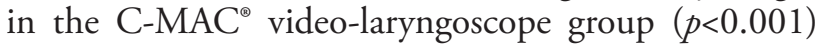
(Table 1).

There was no statistically significant difference between the groups in terms of the hemodynamic responses to laryngoscopy and intubation. The HR and MAP values were increased in all groups in the first minute after intubation, but there was no statistical significance $(p>0.05)$ (Tables $2 \& 3$ ).

The comparisons of the mean HR values for each time period within the groups are presented in Table 2. In the McCoy group, the temporal changes in the HR values were statistically significant $(p=0.013)$. The mean HR value at the time T0 before induction was not significantly different from all other times,

Table 1 - Comparison of the groups' demographic characteristics, ASA-Mallampati scores and intubation times.

\begin{tabular}{|c|c|c|c|c|c|}
\hline $\begin{array}{l}\text { Demographic } \\
\text { characteristics }\end{array}$ & $\begin{array}{l}\text { Total } \\
(\mathbf{n}=90)\end{array}$ & $\begin{array}{l}\text { McCoy } \\
(\mathbf{n}=30)\end{array}$ & $\begin{array}{c}\text { Macintosh } \\
(\mathrm{n}=30)\end{array}$ & $\begin{array}{c}\text { C-MAC } \\
(\mathbf{n}=30)\end{array}$ & $P$-value \\
\hline Gender (F/M)(n) & $67 / 23$ & $25 / 5$ & $20 / 10$ & $22 / 8$ & 0.330 \\
\hline Age (years) & $40.64 \pm 12.26$ & $40.87 \pm 12.75$ & $41.53 \pm 11.31$ & $39.53 \pm 12.99$ & 0.816 \\
\hline Weight (kg) & $70.70 \pm 13.84$ & $65.87 \pm 12.85$ & $72.93 \pm 14.16$ & $73.30 \pm 13.64$ & 0.062 \\
\hline ASA (I/II) & $36 / 54$ & $10 / 20$ & $11 / 19$ & $15 / 15$ & 0.387 \\
\hline Mallampati (I/II) & $47 / 43$ & $15 / 15$ & $14 / 16$ & $18 / 12$ & 0.569 \\
\hline Intubation time (s) & $16.53 \pm 5.92$ & $15.37 \pm 5.19^{\mathrm{a}}$ & $14.33 \pm 4.16^{a}$ & $19.90 \pm 6.71^{\mathrm{b}}$ & $<0.001$ \\
\hline
\end{tabular}


Table 2 - Comparison of heart rates within and between groups.

\begin{tabular}{lcccc}
\hline Time $(\min )$ & McCoy $(\mathbf{n}=30)$ & Macintosh $(\mathrm{n}=30)$ & C-MAC $^{*}(\mathbf{n}=30)$ & $P$-value \\
\hline T0 & $84.77 \pm 18.67^{\mathrm{ab}}$ & $76.80 \pm 13.77^{\mathrm{ab}}$ & $78.87 \pm 14.33^{\mathrm{ab}}$ & 0.133 \\
T1 & $91.73 \pm 10.60^{\mathrm{a}}$ & $91.13 \pm 12.85^{\mathrm{c}}$ & $86.73 \pm 13.68^{\mathrm{a}}$ & 0.242 \\
T3 & $87.27 \pm 11.61^{\mathrm{c}}$ & $86.27 \pm 14.76^{\mathrm{a}}$ & 0.797 \\
T5 & $88.47 \pm 11.22^{\mathrm{a}}$ & $82.90 \pm 11.63^{\mathrm{b}}$ & $83.27 \pm 14.75^{\mathrm{a}}$ & 0.345 \\
T10 & $87.17 \pm 10.72^{\mathrm{a}}$ & $77.57 \pm 13.11^{\mathrm{a}}$ & $80.47 \pm 14.37^{\mathrm{b}}$ & 0.331 \\
\hline
\end{tabular}

T0: before induction, T1: $1 \mathrm{~min}$ after intubation, T3: $3 \mathrm{~min}$ after intubation, T5: $5 \mathrm{~min}$ after intubation, T10: 10 min after intubation. p-value: comparison between groups. a-c: There is no difference between times with the same letter in a group.

Table 3 - Comparison of mean arterial pressures within and between groups.

\begin{tabular}{|c|c|c|c|c|}
\hline Time (min) & $\operatorname{McCoy}(n=30)$ & Macintosh $(\mathrm{n}=30)$ & C-MAC" (n=30) & $P$-value \\
\hline T0 & $97.67 \pm 24.43^{\mathrm{bc}}$ & $100.03 \pm 15.32^{\mathrm{bc}}$ & $98.63 \pm 12.14^{c}$ & 0.878 \\
\hline T1 & $101.90 \pm 19.76^{\mathrm{b}}$ & $108.03 \pm 22.83^{c}$ & $101.77 \pm 21.03^{c}$ & 0.430 \\
\hline T3 & $91.90 \pm 20.99^{\mathrm{b}}$ & $92.73 \pm 16.14^{\mathrm{b}}$ & $89.73 \pm 18.51^{b c}$ & 0.814 \\
\hline T5 & $83.57 \pm 17.48^{\mathrm{ac}}$ & $86.13 \pm 14.72^{\mathrm{a}}$ & $86.10 \pm 16.44^{\mathrm{ab}}$ & 0.782 \\
\hline T10 & $78.30 \pm 11.47^{\mathrm{a}}$ & $80.40 \pm 14.50^{\mathrm{a}}$ & $79.43 \pm 11.53^{\mathrm{a}}$ & 0.811 \\
\hline \multicolumn{5}{|c|}{$\begin{array}{l}\text { T0: before induction, T1: } 1 \mathrm{~min} \text { after intubation, T3: } 3 \mathrm{~min} \text { after intubation, } \mathrm{T} 5: 5 \mathrm{~min} \text { after intubation, } \\
\text { T10: } 10 \mathrm{~min} \text { after intubation. p-value: comparison between groups. } \\
\text { a-c: There is no difference between times with the same letter in a group }\end{array}$} \\
\hline
\end{tabular}

whereas the value at T10 after intubation was lower than those at T1, T3 and T5. In the Macintosh group, the temporal changes of the HR mean values were statistically significant $(p<0.001)$. The HR value obtained at $\mathrm{T} 0$ before induction was lower than the T1 and T3 measurements after intubation. The T1 and T3 measurements after intubation were also different from the T5 and T10 measurements after intubation. After intubation, the value obtained at T10 was lower than that obtained at $\mathrm{T} 5$. In the $\mathrm{C}^{-\mathrm{MAC}^{\odot}}$ videolaryngoscope group, the temporal variation of the HR mean values was also statistically significant $(p=0.001)$. The value obtained at T0 before induction was not significantly different from all other times, whereas the value obtained at T10 after intubation was lower than the values at $\mathrm{T} 1, \mathrm{~T} 3$, and $\mathrm{T} 5$.

The comparisons of MAP for each time period within the groups are presented in Table 3. In the McCoy group, the mean MAP value at the time T0 before induction was higher than the value at T10 after intubation. The MAP values at T1 and T3 after intubation were also higher than the T5 and T10 values $(p<0.001)$. In the Macintosh group, the mean MAP value obtained at the time T0 before induction was higher than the values at T5 and T10 after intubation. Similarly, the MAP value at the time $\mathrm{T} 1$ after intubation was higher than those at T3, T5 and T10 $(p<0.001)$. In the C-MAC videolaryngoscope group, the mean MAP value obtained at the time T0 before induction was higher than the values at T5 and T10 after intubation. The MAP values at T10 after intubation were also lower than those at T0, T1 and T3 $(p<0.001)$.

An increase in the ONSD measurements observed immediately after laryngoscopy and intubation was seen in all groups, but there was no statistically significant difference between them $(p>0.05)$ (Tables 4 \& 5). Table 4 shows the change in the mean values of the right eye ONSD measurements for each time period within the groups. In the McCoy group, the mean values of the right eye ONSD measurements were significantly different. The ONSD value obtained at T0 before induction was lower than the values obtained at $\mathrm{T} 1$ and 
Table 4 - Comparison of right-eye ONSD measurements within and between groups.

\begin{tabular}{lcccc}
\hline Time $(\min )$ & McCoy $(\mathbf{n}=30)$ & Macintosh $(\mathbf{n}=30)$ & C-MAC $^{*}(\mathbf{n}=30)$ & $P$-value \\
\hline T0 & $3.65 \pm 0.64^{\mathrm{b}}$ & $3.98 \pm 0.59^{\mathrm{ad}}$ & $3.88 \pm 0.78$ & 0.159 \\
T1 & $4.08 \pm 0.58^{\mathrm{a}}$ & $4.32 \pm 0.57^{\mathrm{bc}}$ & $4.09 \pm 0.65$ & 0.227 \\
T3 & $4.04 \pm 0.59^{\mathrm{a}}$ & $4.24 \pm 0.59^{\mathrm{bd}}$ & $4.11 \pm 0.66$ & 0.440 \\
T5 & $3.87 \pm 0.81^{\mathrm{ab}}$ & $4.06 \pm 0.65^{\mathrm{ac}}$ & $4.06 \pm 0.81$ & 0.520 \\
T10 & $3.81 \pm 0.66^{\mathrm{ab}}$ & $3.89 \pm 0.53^{\mathrm{a}}$ & $4.05 \pm 0.67$ & 0.340 \\
\hline
\end{tabular}

T0: before induction, T1: $1 \mathrm{~min}$ after intubation, T3: $3 \mathrm{~min}$ after intubation, T5: $5 \mathrm{~min}$ after intubation, T10: 10 min after intubation. P-value: comparison between groups. a-d: There is no difference between times with the same letter in a group.

Table 5 - Comparison of left-eye optic nerve sheath diameter measurements within and between groups.

\begin{tabular}{lcccc}
\hline Time $(\min )$ & McCoy $(\mathbf{n}=30)$ & Macintosh $(\mathbf{n}=30)$ & C-MAC $^{*}(\mathbf{n}=30)$ & $P$-value \\
\hline T0 & $3.70 \pm 0.55^{\mathrm{b}}$ & $3.87 \pm 0.40^{\mathrm{ac}}$ & $3.85 \pm 0.60$ & 0.364 \\
T1 & $4.02 \pm 0.64^{\mathrm{a}}$ & $4.26 \pm 0.58^{\mathrm{b}}$ & $3.96 \pm 0.59$ & 0.137 \\
T3 & $3.97 \pm 0.62^{\mathrm{ab}}$ & $4.09 \pm 0.52^{\mathrm{bc}}$ & $3.98 \pm 0.55$ & 0.661 \\
T5 & $3.94 \pm 0.66^{\mathrm{a}}$ & $4.02 \pm 0.56^{\mathrm{ab}}$ & $4.00 \pm 0.66$ & 0.894 \\
T10 & $3.77 \pm 0.67^{\mathrm{ab}}$ & $3.84 \pm 0.45^{\mathrm{a}}$ & $3.94 \pm 0.75$ & 0.572 \\
\hline
\end{tabular}

T0: before induction, T1: 1 min after intubation, T3: 3 min after intubation, T5: 5 min after intubation, T10: 10 min after intubation. p-value: comparison between groups. a-c: There is no difference between times with the same letter in a group

T3 after intubation $(p<0.001)$. There was no difference between the other times. In the Macintosh group, the mean values of the right eye ONSD measurements were significantly different. The ONSD value obtained at T0 before induction was lower than that at T1. Similarly, the T10 value was lower than the T1 and T3 values $(p=0.003)$. In the $\mathrm{C}^{-\mathrm{MAC}^{\circledR}}$ video-laryngoscope group, the mean values of the ONSD measurements of the right eye did not significantly differ $(p=0.291)$.

Table 5 shows the change in the mean values of the left eye ONSD measurements for each time period within the groups. The mean values of the ONSD measurements in the left eye differed in the McCoy group. The value obtained at T0 was lower than those at T1 and T5 ( $p=0.002)$. In the Macintosh group, there was also a difference between the mean values: the ONSD value obtained at $\mathrm{T} 0$ was lower than that at $\mathrm{T} 1$, and the value at $\mathrm{T} 10$ was lower than those at $\mathrm{T} 1$ and $\mathrm{T} 3$

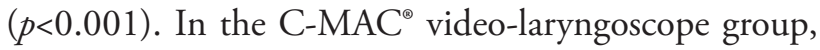
the mean values of the ONSD measurements of the left eye were not significantly different $(p=0.505)$.
Discussion. In this study, in which the effects of 3 different laryngoscopes (the McCoy and Macintosh

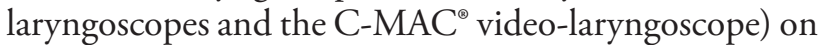
hemodynamic response to laryngoscopy and intubation and ONSD in patients with normal airway were evaluated, there was no significant difference among the groups. However, the intragroup comparisons showed that the increase in HR was significantly higher in the first and third minutes after intubation compared to the baseline value only in the case of using the Macintosh laryngoscope. The increase in the MAP values was similar in all 3 laryngoscope groups compared to the baseline value, and in the first minute after intubation, it did not change significantly. The ONSD measurements were significantly increased at T1 compared to the baseline values in the use of the McCoy and Macintosh laryngoscopes, whereas the HR and ONSD measurements were not significantly

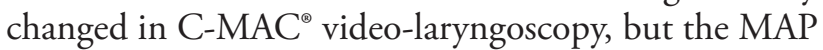
values were significantly increased at T5 and T10 after intubation. The intubation time of $\mathrm{C}^{-\mathrm{MAC}^{\oplus}}$ videolaryngoscopy was significantly longer than the others. 
Physiopathological changes due to laryngoscopy and intubation are important. While these temporary changes do not cause problems for some patients, they may cause more serious hemodynamic responses in patients with cardiovascular pathology, cerebral aneurysm and intracranial hypertension. ${ }^{1-4}$

In addition to various induction regimens used to reduce or prevent hemodynamic responses to laryngoscopy and intubation, alternative laryngoscopes used to facilitate laryngoscopy and improve the glottic appearance have also been reported. ${ }^{1,4-23}$ In studies investigating the effects of the McCoy and Macintosh laryngoscopes and $\mathrm{C}^{-\mathrm{MAC}^{\ominus}}$ video-laryngoscope on hemodynamic responses, different results have been reported. ${ }^{5-23}$ Along with studies stating that the C-MAC ${ }^{\oplus}$ video-laryngoscopy and Macintosh laryngoscopy methods have similar effects on hemodynamic response, others have stated that the $\mathrm{C}^{-\mathrm{MAC}^{\circ}}$ videolaryngoscopy method reduces hemodynamic response, and the lower lift force applied to the supraglotticregion with video-laryngoscopy may be effective in this response. ${ }^{11,12,16,18,22,23}$ In contrast, other studies demonstrated an increased hemodynamic response by C-MAC ${ }^{\oplus}$ video-laryngoscopy. ${ }^{11}$ In their study comparing the cardiovascular changes and catecholamine concentrations during orotracheal intubations with the McCoy and Macintosh laryngoscopes, McCoy et $\mathrm{al}^{6}$ reported that the McCoy blade caused less stress response, stating that this could be due to the reduced lifting force on the base of the tongue required to obtain a clear image of the glottis. In another study, it was reported that McCoy and Macintosh laryngoscopy procedures cause similar hemodynamic responses, and the same blade design of the 2 laryngoscopes can cause a similar stress response in the oral cavity/ pharynx. ${ }^{15}$ While there was no difference in this study in the hemodynamic response between the McCoy and Macintosh laryngoscopes in ASA I-II patients, in a study comparing the hemodynamic response to intubation with McCoy and the Macintosh laryngoscopes and C-MAC ${ }^{\ominus}$ video-laryngoscope, Sarkılar et al ${ }^{15}$ reported an increased hemodynamic response to the Macintosh laryngoscope and $\mathrm{C}_{-} \mathrm{MAC}^{\odot}$ video-laryngoscope in cardiac surgery patients. ${ }^{12}$ The results of this study, which did not show any difference in the hemodynamic response to laryngoscopy and intubation between all 3 laryngoscopy methods, concurred with the literature. The similarities in the hemodynamic response between the groups may be due to the inclusion of patients with normal airways and Mallampati and ASA scores $\leq 3$ and preservation of hemodynamic stability by providing titration of the drug doses administered during induction by BIS monitoring. Additionally, nonstandard narcotic analgesic and lidocaine doses used during induction of anaesthesia may be the cause of differences in hemodynamic response to laryngoscopy and intubation in different studies. Finally, the fact that all 3 laryngoscope blades had the same structure may have affected this study's results.

Traditionally, ICP is measured by brain imaging or invasive monitoring. ${ }^{25,37}$ However, the measurement of ONSD using ultrasound to evaluate ICP has generated considerable interest in the last decade. ${ }^{26-33}$ The intraoperative use of ONSD has gained popularity, and many studies have evaluated ONSD in anesthesia applications. ${ }^{26-34}$ In a meta-analysis of ONSD in laparoscopic surgeries, it was found that the increase in ICP at the early and late stages of pneumoperitoneum could be evaluated by ONSD measurement. ${ }^{26}$ In a study performed in robotic prostate surgeries, ONSD increased in a time-dependent manner following baseline measurement after pneumoperitoneum and a 45 degrees Trendelenburg position. ${ }^{33}$ In their study comparing the effects of anesthetics on ICP in robotic prostate cancer operations, Yu et $\mathrm{al}^{34}$ demonstrated that ONSD was lower in patients receiving propofol infusion after 30 minutes than those receiving sevoflurane.

Although ICP changes correlate strongly with expansion and changes in ONSD, the cut-off value of the minimum ONSD for detection of intracranial hypertension cannot be fully determined, namely, if an increase in ONSD is detected, strong values are needed to initiate treatment quickly. ${ }^{35-37}$ As with other ultrasonographic studies, ONSD measurement is dependent on the evaluator and is therefore subject to error and variability. However, variability in ONSD measurement may be minimized, as the measurement methodology is well standardised, and the results are highly reproducible, unlike more complex ultrasonographic imaging techniques. ${ }^{37}$ In this study, to minimise interpersonal measurement variations, each measurement was performed by three people, and their averages were evaluated. Moreover, instead of using a certain cut-off ONSD value, it was determined that comparing the ONSD changes over time could provide more accurate results, and the data were interpreted accordingly. The effects of laryngoscopy and intubation performed with the McCoy and Macintosh laryngoscopes and the $\mathrm{C}-\mathrm{MAC}^{\oplus}$ video-laryngoscope on ONSD were similar in this study, and only C-MAC ${ }^{\oplus}$ video-laryngoscopy showed no significant change in the ONSD values between measurement times. The increases observed in the first minute after intubation in all three groups were considered consistent with 
response to intubation. The intragroup comparisons showed that the ONSD values, which tended to fall in comparison to the first minute after intubation, were not significantly different but continued to increase up to three minutes after intubation in the C-MAC ${ }^{\odot}$ video-laryngoscope group. This is thought to be due

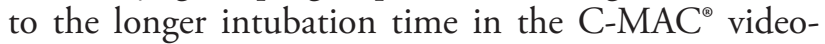
laryngoscope group.

Laryngoscopy time is an important variable which affects the degree of hemodynamic response to intubation. The hemodynamic response's magnitude increases with the strength and duration of laryngoscopy and may also be influenced by long-term intubation. ${ }^{2}$ Moreover, studies have reported both longer and shorter intubation times in different video-laryngoscope procedures in comparison to classical laryngoscopes. ${ }^{12,13,18}$ It has been reported that a long intubation time does not affect hemodynamic parameters in intubations performed with the C-MAC ${ }^{\odot}$ video-laryngoscope. ${ }^{12,13}$ In this study, the possible reasons for the longer time needed for intubation with

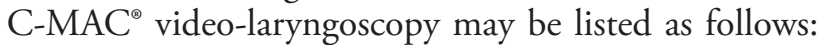
the video-laryngoscope blade covers a larger area in the oral cavity, and the tongue pushed to the left reduces the space available for insertion of the tube into the oral cavity during intubation; fogging of the videolaryngoscope lens prevents clear visualization of the glottis due to non-inhaled gases, and C-MAC ${ }^{\oplus}$ videolaryngoscopy requires greater hand-eye coordination in comparison to conventional laryngoscopies.

Study limitations. Firstly, the major limitation was the difficulty in blinding with this study design, which could have led to a potential study bias. However, a separate anesthesiologist who did not know the type of laryngoscopy was involved in the data collection process. It was impossible to blind the intubating anaesthetist for the laryngoscope being used. Second of all, the arterial blood pressure was not invasively monitored because of the ethics committee's concerns. Thirdly, the study population comprised patients with ASA I-II with a normal airway. Therefore, the results cannot be extrapolated to other patient groups with concomitant medical problems or anticipated difficult airways. Furthermore, the catecholamine levels were not detected during the laryngoscopy process. Finally, the force applied on the base of the tongue was not measured, which could have enlightened the correlation between the amount of force applied to the supraglottic tissues and the neuroendocrine response to the force used.

In conclusion, in patients with normal airways, the McCoy and Macintosh laryngoscopes and the C-MAC ${ }^{\oplus}$ video-laryngoscope had similar effects on the ONSD and haemodynamic response to laryngoscopy and intubation. Only C-MAC ${ }^{\circledast}$ video-laryngoscopy showed a significant increase in the ONSD values during the measurement periods, although the intubation time was longer. It was concluded that intubations with C-MAC ${ }^{\circ}$ video-laryngoscopy would be more appropriate in patients with possible ICP increase. Further studies are needed to explain the effects of ONSD measurements on ICP in glaucoma, ophthalmic surgery or intracranial pressure elevation cases, rather than in a healthy patient population.

\section{References}

1. Butterworth IV JF, Mackey DC, Wasnick JD.Airway Management. In: Morgan \& Mikhail's Clinical Anesthesiology. 5th edn. New York: McGraw Hill; 2013. p. 309-341.

2. Shribman AJ, Smith G, Achola KJ. Cardiovascular and catecholamine responses to laryngoscopy with and without tracheal intubation. Br J Anaesth 1987; 59: 295-299.

3. Mallick A, Klein H, Moss E. Prevention of cardiovascular response to tracheal intubation. Br J Anaesth 1996; 77: 296-297.

4. Stone DJ, Gal TJ. Airway Management.In Miller RD ed. Anesthesia. 5th ed. NewYork (NY): Churchill Livingstone; 2000. p. 1444-1445.

5. Tewari P, Gupta D, Kumar A, Singh U. Opioid sparing during endotracheal intubation using mccoy laryngoscope in neurosurgical patients: the comparison of haemodynamic changes with macintosh blade in a randomized trial. Postgrad Med 2005; 51: 260-264.

6. McCoy EP, Mirakhur RK, McCloskey BV. A comparison of the stress response to laryngoscopy. The Macintosh versus the McCoy blade. Anaesthesia 1995; 50: 943-946.

7. Lewis SR, Butler AR, Parker J, Cook TM, Schofield-Robinson OJ, Smith AF. Videolaryngoscopy versus direct laryngoscopy for adult patients requiring tracheal intubation: a Cochrane Systematic Review. Br J Anaesth 2017; 119: 369-383.

8. Kaur S, Gupta A, Ranjana R. Intubating conditions and stress response to laryngoscopy: Comparison between Macintosh and levering (McCoy's Type) laryngoscope. J Anaesth Clin Pharmacol 2009; 25: 333-336.

9. Nishiyama T, Higashizawa T, Bito H, Konishi A, Sakai T. Which laryngoscope is the most stressful in laryngoscopy; Macintosh, Miller, or McCoy? Masui 1997; 46: 1519-1524.

10. Abdelgawad AF, Shi QF, Halawa MA,Wu ZL, Wu ZY, Chen $\mathrm{XD}$, et al. Comparison of cardiac output and hemodynamic responses of intubation among different video laryngoscopies in normotensive and hypertensive patients. J Huazhong Univ Sci Technolog Med Sci 2015; 35: 432-438.

11. Buhari F, Selvaraj V. Randomized controlled study comparing the hemodynamic response to laryngoscopy and endotracheal intubation with McCoy, Macintosh, and C-MAC laryngoscopes in adult patients. J Anaesthesiol Clin Pharmacol 2016; 32: 505-509.

12. Sarkılar G, Sargın M, Sarıtaş TB,Borazan H, Gök F, Kılıçaslan A, et al. Hemodynamic responses to endotracheal intubation performed with video and direct laryngoscopy in patients scheduled for majör cardiac surgery. Int J ClinExp Med 2015; 8: 11477-11483. 
13. Kanchi M, Nair HC, Banakal S, Murthy K, Murugesan C. Haemodynamic response to endotracheal intubation in coronary artery disease: Direct versus video laryngoscopy. Indian J Anaesth 2011; 55: 260-265.

14. Kihara S, Brimacombe J, Yaguchi Y, Watanabe S, Taguchi N, Komatsuzaki T. Hemodynamic responses among three tracheal intubation devices in normotensive and hypertensive patients. Anesth Analg 2003; 96: 890-895.

15. Shin HJ, Shin YD, Kim ST. The effect of tracheal intubation with the McCoy or Macintosh laryngoscope on the blood pressure and heart rate during propofol-remifentanil induction. Korean J Anesthesiol 2009; 56: 387-391.

16. Aggarwal H, Kaur S, Baghla N, Kaur S. Hemodynamic response to orotracheal intubation: Comparison between Macintosh, McCoy, and C-MAC Video Laryngoscope. Anesth Essays Res 2019; 13: 308-312.

17. Haidry MA, Khan FA. Comparison of hemodynamic response to tracheal intubation with Macintosh and McCoy laryngoscopes. J Anaesthesiol Clin Pharmacol 2013; 29: 196-199.

18. Aziz MF, Dillman D, Fu R, Brambrink AM. Comparative effectiveness of the C-MAC video laryngoscope versus direct laryngoscopy in the setting of the predicted difficult airway. Anesthesiology 2012; 116: 629-636.

19. Jephcott A. The Macintosh Laryngoscope. Anaesthesia 1984; 39: 474-479.

20. McCoy EP, Mirakhur RK. The levering laryngoscope. Anaesthesia 1993; 48: 516-519.

21. Cavus E, Kieckhaefer J, Doerges V, Moeller T, Thee C, Wagner $\mathrm{K}$. The C-MAC video laryngoscope: first experiences with a new device for video laryngoscopy-guided intubation. Anesth Analg 2010; 110: 473-477.

22. Piepho T, Fortmueller K, Heid FM, Schmidtmann I, Werner C, Noppens RR. Performance of the C-MAC video laryngoscope in patients after a limited glottic view using Macintosh laryngoscopy. Anaesthesia 2011; 66: 1101-1105.

23. Cavus E, Thee C, Moeller T, Kieckhaefer J, Doerges V, Wagner K. A randomised, controlled crossover comparison of the C-MAC videolaryngoscope with direct laryngoscopy in 150 patients during routine induction of anaesthesia. BMC Anesthesiol 2011; 11: 6.

24. Butterworth IV JF, Mackey DC, Wasnick JD. Airway Management. In: Morgan \& Mikhail's Clinical Anesthesiology. 5th edn. New York: McGraw Hill, 2013, p. 575-592.

25. Guillaume J, Janny P. Continuous intracranial manometry; physiopathologic and clinical significance of the method. Presse Med 1951; 59: 953-955.
26. Dubourg J, Javouhey E, Geeraerts T, Messerer M, Kassai B. Ultrasonography of optic nerve sheath diameter for detection of raised intracranial pressure: a systematic review and metaanalysis. Intensive Care Med 2011; 37: 1059-1068.

27. Maissan IM, Dirven PJ, Haitsma IK, Hoeks SE, Gommers D, Stolker RJ. Ultrasonographic measured optic nerve sheath diameter as an accurate and quick monitor for changes in intracranial pressure. J Neurosurg 2015; 123: 743-747.

28. Hansen HC, Helmke K. The subarachnoid space surrounding the optic nerves: an ultrasound study of the optic nerve sheath. Surg Radiol Anat 1996; 18: 323-328.

29. Khan MN, Shallwani H, Khan MU, Shamim MS. Noninvasive monitoring intracranial pressure. A review of available modalities. Surg Neurol Int 2017; 8: 51.

30. Shah SB, Bhargava AK, Choudhury I. Noninvasive intracranial pressure monitoring via optic nerve sheath diameter for robotic surgery in steep trendelenburg position. Saudi J Anaesth 2015; 9: 239-246.

31. Kim EJ, Koo BN, Choi SH, Park K, Kim MS. Ultrasonographic optic nerve sheath diameter for predicting elevated intracranial pressure during laparoscopic surgery: a systematic review and meta-analysis. Surg Endosc 2018; 32: 175-182.

32. Kim MS, Bai SJ, Lee JR, Choi YD, Kim YJ, Choi SH. Increase in intracranial pressure during carbon dioxide pneumoperitoneum with steep trendelenburg positioning proven by ultrasonographic measurement of optic nerve sheath diameter. J Endourol 2014; 28: 801-806.

33. Whiteley JR, Taylor J, Henry M, Epperson TI, Hand WR. Detection of elevated intracranial pressure in robot-assisted laparoscopic radical prostatectomy using ultrasonography of optic nerve sheath diameter. J Neurosurg Anesthesiol 2015; 27 : 155-159.

34. Yu J, Hong JH, Park JY, Hwang JH, Cho SS, Kim YK. Propofol attenuates the increase of sonographic optic nerve sheath diameter during robot-assisted laparoscopic prostatectomy: a randomized clinical trial. BMC Anesthesiology 2018; 18: 72.

35. Patterson DF, Ho ML, Leavitt JA,Smischney NJ, Hocker SE, Wijdicks EF, et al. Comparison of ocular ultrasonography and magnetic resonance imaging for detection of increased intracranial pressure. Front Neurol 2018; 9: 278.

36. Rajajee V, Vanaman M, Fletcher JJ, Jacobs TL. Optic nerve ultrasound for the detection of raised intracranial pressure. Neurocritical Care 2011; 15: 506-515.

37. Ballantyne SA, O'Neill G, Hamilton R, Hollman AS. Observer variation in the sonographic measurement of optic nerve sheath diameter in normal adults. Eur J Ultrasound 2002; 15 : 145-149. 